\title{
Alginate type and RGD density control myoblast phenotype
}

\author{
Jon A. Rowley, ${ }^{1}$ David J. Mooney ${ }^{1,2,3}$ \\ ${ }^{1}$ Department of Biomedical Engineering, University of Michigan, Colleges of Engineering and Dentistry, \\ Ann Arbor, Michigan \\ ${ }^{2}$ Department of Chemical Engineering, University of Michigan, Colleges of Engineering and Dentistry, \\ Ann Arbor, Michigan \\ ${ }^{3}$ Department of Biologic and Materials Science, University of Michigan, Colleges of Engineering and Dentistry, \\ Ann Arbor, Michigan
}

Received 15 September 2000; revised 5 March 2001; accepted 30 May 2001

\begin{abstract}
Alginates are being increasingly used for cell encapsulation and tissue engineering applications; however, these materials cannot specifically interact with mammalian cells. We have covalently modified alginates of varying monomeric ratio with RGD-containing cell adhesion ligands using carbodiimide chemistry to initiate cell adhesion to these polymers. We hypothesized that we could control the function of cells adherent to RGD-modified alginate hydrogels by varying alginate polymer type and cell adhesion ligand density, and we have addressed this possibility by studying the proliferation and differentiation of $\mathrm{C} 2 \mathrm{C} 12$ skeletal myoblasts adherent to these materials. RGD density on alginates of varying monomeric ratio could be controlled
\end{abstract}

over several orders of magnitude, creating a range of surface densities from 1-100 $\mathrm{fmol} / \mathrm{cm}^{2}$. Myoblast adhesion to these materials was specific to the RGD ligand, because adhesion could be competed away with soluble RGD in a dosedependent manner. Myoblast proliferation and differentiation could be regulated by varying the alginate monomeric ratio and the density of RGD ligands at the substrate surface, and specific combinations of alginate type and RGD density were required to obtain efficient myoblast differentiation on these materials. (C) 2002 John Wiley \& Sons, Inc. J Biomed Mater Res 60: 217-223, 2002

Key words: tissue engineering; RGD; alginates; skeletal muscle; biomaterial design

\section{INTRODUCTION}

Biomaterials have recently been required to provide increasingly sophisticated functions in a variety of applications, including tissue engineering. ${ }^{1-3}$ In tissue engineering, biomaterials are used as scaffolds to guide the development of new tissues and organs from transplanted or native cells. ${ }^{2,3}$ To direct cell and tissue response, biomaterial design has focused on controlling the material's chemistry for promotion of highly specific binding interactions between the material and surrounding cells. This is typically accomplished by presentation from the material surface dis-

Correspondence to: D. J. Mooney; e-mail: mooneyd@ umich.edu

Contract grant sponsor: National Institutes of Health; contract grant number R01-DE13349.

Contract grant sponsor: Michigan Cellular Biotechnology Training Program.

(C) 2002 John Wiley \& Sons, Inc. DOI $10.1002 / j b m .1287$ tinct extracellular matrix or peptide ligands specific to cell surface receptors, and /or controlling the density, spatial presentation, or combinations of these ligands from the material. ${ }^{4-6}$ The ligand density may regulate the material's ability to resist cell-based tractional forces after adhesion ${ }^{7}$ and thus mediate changes in cell morphology. Cell morphology has been clearly demonstrated to correlate with gene expression at a number of levels. ${ }^{8}$

Alginates are naturally occurring polysaccharides that gel in the presence of divalent cations. ${ }^{9}$ Alginates are copolymers containing mannuronic acid $(\mathrm{M})$ and guluronic acid $(\mathrm{G})$ monomeric subunits of varying amounts and distribution along the polymer backbone. ${ }^{9}$ These subunits differ in their ability to contribute to hydrogel cross-linking and thus alter the physical properties of the resultant hydrogels. ${ }^{10}$ Because of their gentle gelling properties, alginates are widely used for cell encapsulation in vitro ${ }^{11}$ and in vivo ${ }^{12}$ and for several tissue engineering applications. ${ }^{13,14}$ Alginates of varying monomeric ratios (M:G ratio) demonstrate varying biocompatibilities in vivo. ${ }^{15-17} \mathrm{We}$ have modified alginates of varying $M: G$ ratios with 
RGD-containing peptide sequences ${ }^{18}$ to obtain celladhesion substrates with controllable chemical and cell-adhesive properties for model in vitro studies. Unlike other model cell culture systems, modified alginates translate into in vivo studies quite easily, ${ }^{19-21}$ and variables found to control cell function in vitro may be easily and quickly translated into practical applications.

Skeletal muscle cells provide a convenient model cell system to study how biomaterial design variables may control cell phenotype, because they have biochemically and morphologically distinct proliferative and differentiated phenotypes. ${ }^{22}$ Myoblasts maintained in high serum medium continuously enter the cell cycle and proliferate. Myoblasts transferred to low serum medium $(<2 \%$ serum) irreversibly exit the cell cycle, fuse into multinucleated myofibrils, and upregulate an entire battery of genes not expressed in the proliferative phenotype. ${ }^{22}$ Differentiation-specific genes include transcription factors (e.g., MyoD, myogenin) and functional proteins used in muscle contraction (e.g., muscle creatine kinase $\mathrm{e}^{22,23}$ ). In the current studies, we used C2C12 skeletal myoblasts to address the hypothesis that the ligand density and alginate chemistry alter cell proliferation and differentiation, and we demonstrate that specific combinations of adhesion ligands and $\mathrm{M}: \mathrm{G}$ ratio are required to support myoblast fusion and differentiation. To the author's knowledge, this is the first report that skeletal myoblasts are capable of sustained growth and differentiation on highly specific adhesive substrates without providing whole extracellular matrix (ECM) molecules such as fibronectin, laminin, or collagen.

\section{MATERIALS AND METHODS}

\section{Alginate chemistry}

Ultrapure alginates were purchased from ProNova Biomedical (Norway), and all chemicals were purchased from Sigma (St. Louis, MO) unless otherwise stated. MVG alginate, a high G-containing alginate (M:G ratio of 40:60 as specified by the manufacturer), and MVM alginate, a high M-containing alginate (M:G ratio of 70:30 as specified by the manufacturer) were used in all of the studies. The GGGGRGDY peptide was synthesized at the University of Michigan Protein and Carbohydrate Structure Core facility. Using previously described carbodiimide chemistry, ${ }^{18}$ the carboxylic acids within high M- and high G-containing alginates were modified with GGGGRGDY peptide sequences containing the RGD amino acid sequence capable of mimicking the cell adhesion functionality of human fibronectin. ${ }^{24}$ All reactions were performed in 0.1M MES buffer containing $0.3 \mathrm{M} \mathrm{NaCl}$ at $\mathrm{pH} 6.5$ with an alginate concentration of $1 \%$ $(\mathrm{w} / \mathrm{v})$. EDC was added to the alginate to activate the carboxylic acids along the polymer chain at a 1:20 molar ratio to the uronic acid monomers of the alginate. Sulfo-NHS (Pierce
Chemical) was added as a coreactant at a 1:2 molar ratio to EDC. ${ }^{18}$ Peptide was added to the reaction, and the alginates were allowed to react for $20 \mathrm{~h}$. The modified alginates were purified with extensive dialysis over 3 days. After dialysis, $0.5 \mathrm{~g}$ of activated carbon was added for every 1 gram alginate and removed via filtration to further purify the material. Peptide incorporation was quantified using ${ }^{125}$ I-labeled GGGGRGDY as a tracer, and the peptide was custom iodinated on the C-terminal tyrosine residue by Biomedical Technologies, Inc. (Stoughton, MA). The RGD-ligand density presented at the surface of the alginate hydrogel substrates was calculated, with the assumption that a cell had access to the peptide in the top $5 \mathrm{~nm}$ of the hydrogel surface.

\section{Material processing}

RGD-modified alginates were processed into culture surfaces by casting alginate gels between glass plates and punching out hydrogel disks. The alginates were dissolved $(2 \% \mathrm{w} / \mathrm{v})$ in a solution with $8 \mathrm{~g} / \mathrm{L} \mathrm{NaCl}$ and $4 \mathrm{~g} / \mathrm{L}\left(\mathrm{NaPO}_{4}\right)_{6}$. The solution was sterilized by diluting the alginate to $1 \%$ with $\mathrm{diH}_{2} \mathrm{O}$, sterile filtration, and sterile lyophilization to concentrate the alginate to $2 \%$. A dual syringe method was used to mix 1 part of $21 \mathrm{~g} / \mathrm{L}(\mathrm{v} / \mathrm{v}) \mathrm{CaSO}_{4}$ in water with 25 parts $2 \%$ alginate. The gelling alginate solution was dispensed between parallel glass plates with $0.75-\mathrm{mm}$ spacers, the alginate was allowed to gel for 30-45 $\mathrm{min}$, and circular gel disks were cut out with 12.8-mm hole punches. The alginate disks were equilibrated in DMEM overnight before cell experiments.

\section{Quantifying cell adhesion and proliferation}

C2C12 mouse skeletal myoblasts (ATCC) were maintained in growth medium consisting of DMEM with penicillin/streptomysin (10 units/L) antibiotic and supplemented with 10\% FBS (all from Gibco, Gaithersburg, MD). The myoblasts were maintained in subconfluent cultures at all times before experiments, and media were changed daily to prevent myoblast differentiation and fusion. For proliferation experiments, myoblasts were seeded at approximately 2400 cells $/ \mathrm{cm}^{2}$ onto alginate disks in 24-well plates. The alginate disks were harvested over time and placed in $1 \mathrm{~mL}$ of $0.25 \mathrm{M}$ trypsin for $5 \mathrm{~min}$ to which $9 \mathrm{~mL}$ of $50 \mathrm{mM}$ EDTA in PBS (pH 7.4) was added for 20 min to dissolve the alginate. Cell number was then quantified using a Coulter Counter.

\section{Myoblast differentiation and quantifying differentiation}

Myoblasts were induced to differentiate by culturing in low serum medium with supplements as established elsewhere. $^{22}$ The differentiation medium consisted of DMEM with penicillin/streptomysin (10 units/L) and supple- 
mented with dexamethasone $\left(10^{-7} \mathrm{M}\right.$, Sigma), ITS (insulin, $5 \mathrm{mg} / \mathrm{mL}$; transferrin, $5 \mathrm{mg} / \mathrm{mL}$; sodium selenite, $5 \mathrm{ng} / \mathrm{mL}$; Boehringer Mannheim), and 0.5\% FBS. The myoblasts were seeded to confluence at approximately 80,000 cells $/ \mathrm{cm}^{2}$, and medium was changed daily. Myoblast differentiation was measured qualitatively by cell fusion into multinucleated myofibrils and quantitatively by measuring the activity of muscle creatine kinase, an enzyme not expressed in the proliferative phenotype of myoblasts and upregulated during myoblast differentiation. ${ }^{23}$ Cell protein was collected using passive lysis buffer (Promega, Madison, WI), which is formulated to maintain enzymatic activity of cell protein. Creatine kinase activity was quantified using a colorimetric assay from Sigma (kit 520) that was modified for use with cultured cells.

\section{RESULTS}

\section{Chemistry}

Alginates of varying M:G ratio were covalently modified with RGD-containing peptides to obtain model hydrogel substrates with cell-binding specificity. Radioactively labeled RGD was incorporated onto both high $\mathrm{M}$ and high $\mathrm{G}$ alginates with nearly identical incorporation efficiencies of between $55 \%$ and $60 \%$ (Fig. 1). Less than $0.5 \%$ of the RGD remained in the alginate after dialysis in negative control reactions containing no EDC.

\section{Specificity of cell adhesion}

Integrin-specific adhesion to these materials was demonstrated with the addition of soluble GGGGRGDY

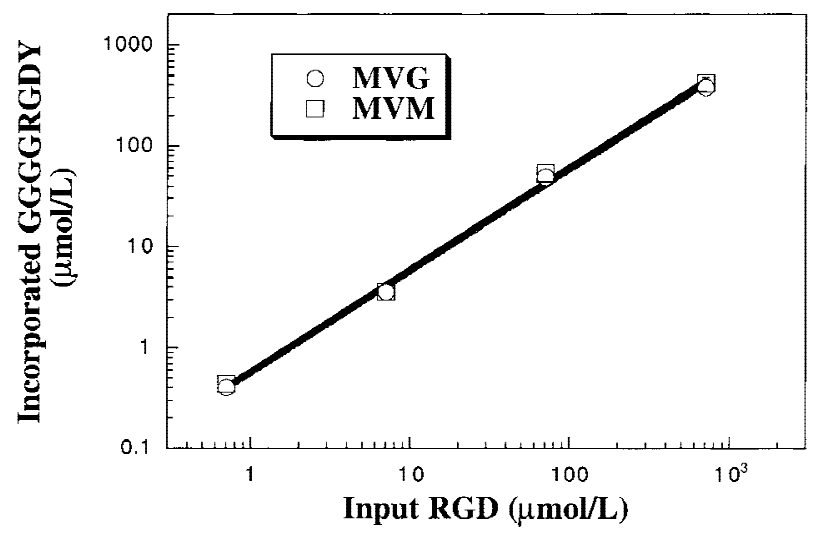

Figure 1. Alginates high in mannuronic acid (MVM, $\square$ ) or guluronic acid (MVG, $O$ ) were modified with the GGGGRGDY peptide with near identical efficiencies over a physiologically relevant range of peptide densities. Values reported are the average and standard deviation with an $n=3$, and the error bars are smaller than the symbols used. Less then $0.5 \%$ of uncoupled peptide remained in the alginate after purification. ligand to the seeding medium. Soluble GGGGRGDY inhibited cell spreading, and all of the cells were round and nonadherent. Quantification of cell adhesion at $4 \mathrm{~h}$ demonstrated that the soluble RGD blocked cell adhesion in a dose-dependent manner (Fig. 2). Addition of the nonadhesive peptide sequence GGGGRGEY (varying by only one $-\mathrm{CH}_{2}$ group from the RGD peptide) to the culture medium had no morphological or adhesion blocking effects on the cells even at the highest peptide concentration (not shown).

\section{Varying alginate M:G ratio at a constant ligand density}

C2C12 skeletal myoblasts were seeded onto the modified alginates (RGD densities of approximately $10 \mathrm{fmol} / \mathrm{cm}^{2}$ ) to test if cell proliferation would be regulated by the M:G ratio of the alginate. $\mathrm{C} 2 \mathrm{C} 12$ myoblasts express RGD-specific integrin receptors (e.g., a5b $1^{25}$ ), and integrin-specific interactions with these materials was expected. Myoblast adhesion at $4 \mathrm{~h}$ was consistent between the adhesion substrates of varying conditions. The rate of proliferation significantly increased as the G-content of the alginate increased [Fig. 3(A)], even though the type and density of the adhesion ligand remained constant.

The differentiation of myoblasts was next studied to determine if this aspect of cell function would also be dependent on alginate polymer type. The initial seeding density was quantified and was the same on all alginate types. The highest G-content substrates promoted extensive fusion of the myoblasts by day 3 [Fig. 3(B)], with subsequently increasing levels of muscle creatine kinase activity over time [Fig. 3(C)],

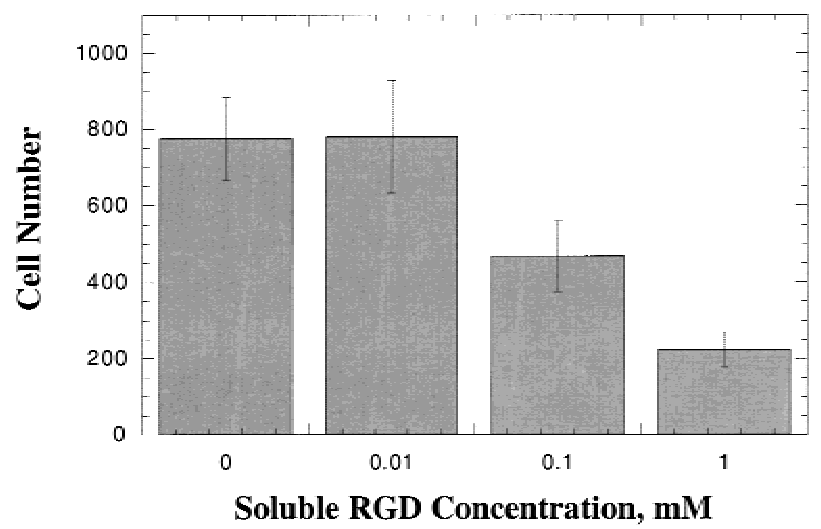

Figure 2. Myoblast adhesion to alginate hydrogels modified with the GGGGRGDY peptides ( $4 \mathrm{~h}$ postseeding) was specific to the coupled peptide, because soluble GGGGRGDY added to the seeding medium inhibits adhesion and spreading of the myoblasts. This inhibition occurs in a dose-dependent manner as adhesion blocking experiments performed in DMEM containing varying concentrations of the GGGGRGDY peptide demonstrated. 


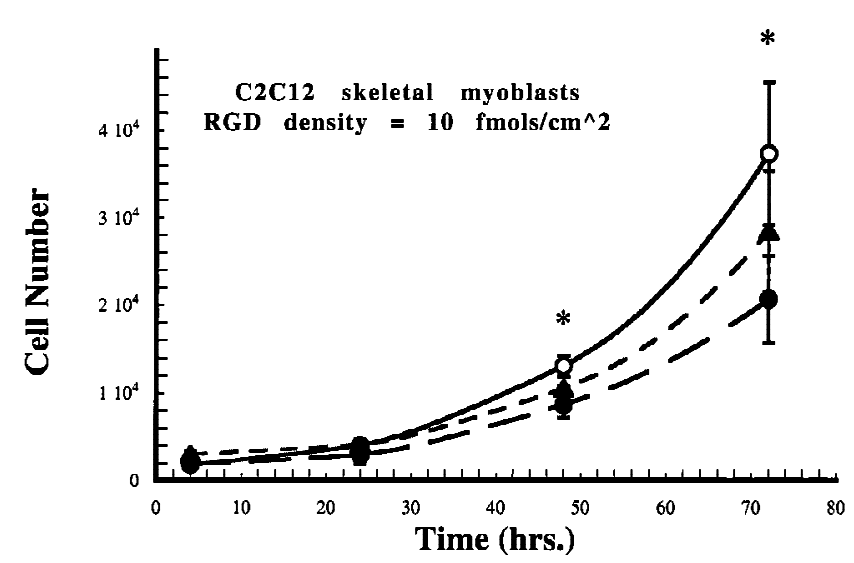

A

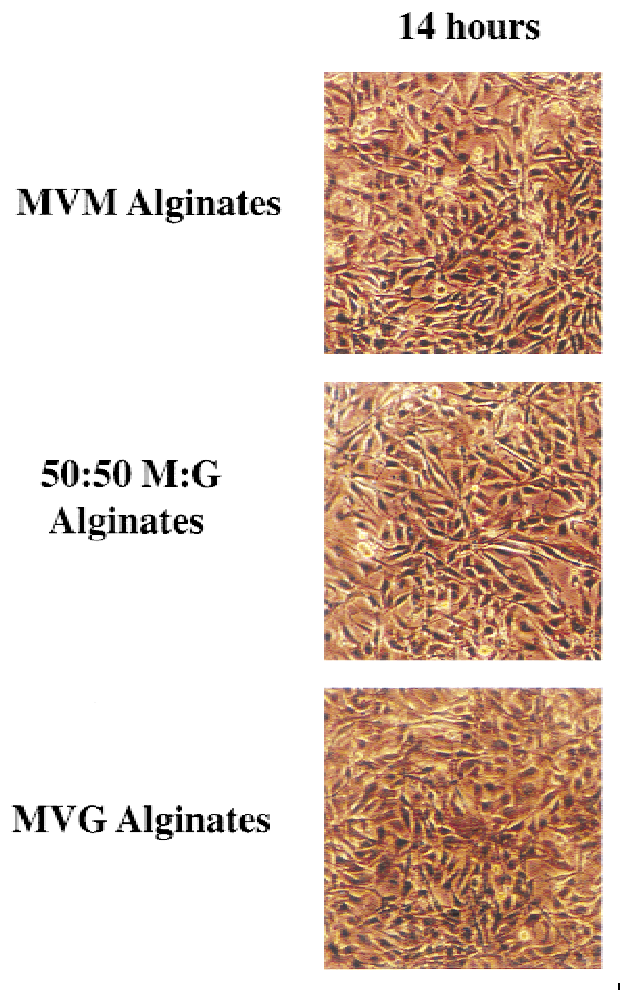

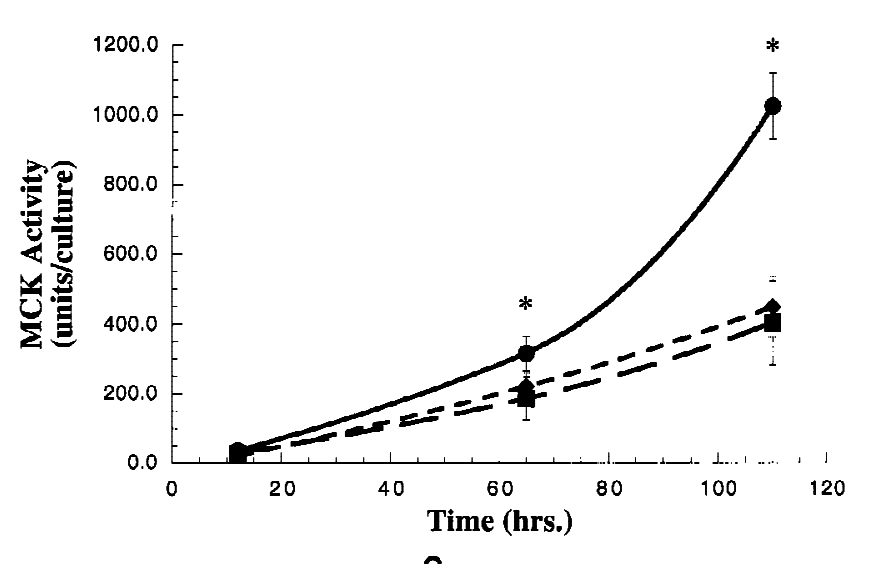

c

65 hours

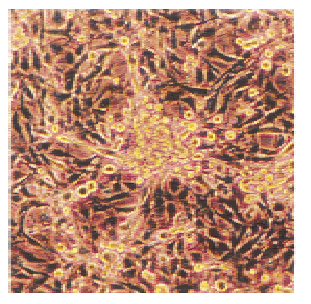

110 hours
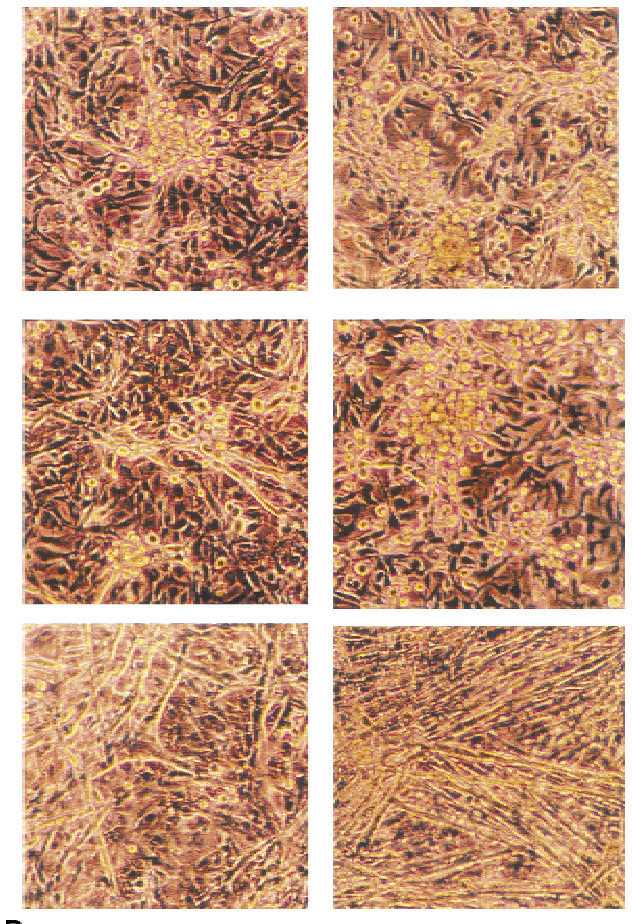

Figure 3. The proliferation and differentiation were controlled by the monomeric ratio of the alginate substrates (myoblasts were cultured on alginates of varying M:G with a constant RGD-ligand density of $10 \mathrm{fmol} / \mathrm{cm}^{2}$ ). (A) Increasing G-content at a constant RGD density led to an increased rate of myoblast proliferation. Myoblasts on MVG $(\bigcirc)$ proliferate faster than on MVM $(\mathbf{O})$ and M:G (50:50 mix of MVG and MVM) $(\boldsymbol{\Delta}) .{ }^{*}$ represents statistically significant differences $(p<0.05)$ in cell counts between conditions. (B) The differentiation of the myoblasts was also highly dependent on the M:G ratio. Initial myoblast seeding densities were consistent between condition, as confirmed with cell counts. The myoblasts readily fused when on the high-G substrates by $65 \mathrm{~h}$ postseeding, whereas the lower-G substrates did not support fusion. The myoblasts on the high-G alginates at $110 \mathrm{~h}$ were highly fused, whereas the two low-G substrates had many rounded cells and multicellular aggregates on the surface, with little fusion. (C) Muscle creatine kinase activity indicated that myoblast differentiation increased over time in the cultures, and was highest on MVG $(\mathbf{)})$ substrates. MVM $(\bullet)$ and M:G $(\boldsymbol{\square})$ substrates did not support myoblast fusion or extensive creatine kinase activity. *Statistically significant differences $(p<0.05)$ in creatine kinase activity between the highest modulus and the two low modulus conditions. [Color figure can be viewed in the online issue, which is available at www.interscience.wiley.com.]

which is consistent with in vitro myogenesis on tissue culture polystyrene substrates. ${ }^{22,23}$ However, the lower G-content adhesion substrates (MVM and 50:50 mixture of M:G alginates) supported little to no fusion over time [Fig. 3(B)]. Many of the myoblasts in the nonfused cultures tended to lose adhesivity to the substrate, and the cultures were a mixture of spread cells, rounded cells, and aggregated cell clumps [Fig. 3(B)]. The creatine kinase activity was significantly lower in these cultures [Fig. 3(C)]. 


\section{Varying ligand density on high G substrates}

We next altered the density of adhesion ligands from 1 to $100 \mathrm{fmol} / \mathrm{cm}^{2}$ on the alginate substrates to determine whether the adhesiveness of the biomaterial would modulate cell phenotype. Stiff substrates with the lowest RGD peptide density $\left(1 \mathrm{fmol} / \mathrm{cm}^{2}\right)$ promoted adhesion and spreading of the myoblasts in a bipolar manner, but the cells retained an rounded morphology. On these hydrogels, the myoblasts grew slowly and formed aggregated cell clusters over time. In contrast, as the RGD density increased to $10 \mathrm{fmol} / \mathrm{cm}^{2}$, the myoblasts were observed to spread to an increasing extent, and the rate of myoblast proliferation increased with increasing ligand density [Fig. 4(A)]. The rate of proliferation reached a maximum at the $30 \mathrm{fmol} / \mathrm{cm}^{2}$ density [Fig. 4(A)], and further increases in the RGD density did not increase the rate of proliferation. Interestingly, raising the ligand density from 10 to $100 \mathrm{fmol} / \mathrm{cm}^{2}$ on the MVM substrates had little to no effect on the rate of myoblast proliferation (data not shown).

The peptide density also modulated myoblast differentiation and fusion. On the MVG alginate substrates at low ligand densities $\left(1 \mathrm{fmol} / \mathrm{cm}^{2}\right)$, myoblasts formed aggregated clusters and differentiated poorly [Fig. 4(B)]. The inability of the myoblasts to fuse at the low RGD densities resulted in low and inconsistent creatine kinase activity [Fig. 4(C)]. Myoblasts cultured at the intermediate ligand density $\left(10 \mathrm{fmol} / \mathrm{cm}^{2}\right)$ began fusing by $24 \mathrm{~h}$ and were extensively fused by day 3 [Fig. 4(B)]. Myoblast fusion was coupled with the characteristic increase in the overall creatine kinase activity [Fig. 4(C)]. The alginate with the highest GGGGRGDY density $\left(100 \mathrm{fmol} / \mathrm{cm}^{2}\right)$ substrates also promoted extensive fusion and increased creatine kinase activity over time, although not to a significantly greater extent than the intermediate ligand density. The ligand density was also increased from 10 to $100 \mathrm{fmol} / \mathrm{cm}^{2}$ on the MVM substrates. However, this order of magnitude increase in ligand density was still insufficient to promote myoblast fusion.

\section{DISCUSSION}

In the current studies, a model hydrogel substrate based on alginate polysaccharides in which one can independently vary the alginate monomeric ratio and the density of adhesion ligands at the material's surface has been developed. With these studies, we have demonstrated that skeletal myoblast proliferation and differentiation are dependent on alginate type and the density of adhesion ligands presented at the material's surface. The ability to control the phenotype of myo- blasts in contact with a biomaterial will be important in several applications where control over specific cell functions or tissue formation are required.

\section{Controlling adhesion substrate chemistry}

We have covalently modified and quantified the incorporation of RGD-containing peptides onto purified alginates of varying monomeric ratios. Quantifying the chemistry with ${ }^{125}$ I-labeled peptide demonstrated that the guluronic acid and the mannuronic acid monomers react to the same extent using EDC chemistry (Fig. 1). This result was expected because the two monomers have the same reactive carboxyl groups with different stereochemistry. Importantly, the peptide type (not shown) and density (Fig. 1) may be easily altered, because these variables have been clearly shown to alter cell phenotype. ${ }^{4-6,26-28}$ Furthermore, there are a number of studies that demonstrate that alginates of varying M:G ratio lead to different in vivo responses to the hydrogels. ${ }^{15-17}$.

\section{Myoblast phenotype is dependent on alginate type and ligand density}

The current data indicate that the alginate type and ligand surface density of a biomaterial substrate can direct cellular phenotype. Myoblast proliferation rates are highly dependent on the M:G ratio [Fig. 3(A)]. This alginate-dependent proliferation may be useful in a number of applications, including tissue engineering, in which one may desire to promote controlled cellspecific expansion and tissue formation. Varying the ligand density also altered the rate of proliferation [Fig. 4(A)] on the high G-content alginates; however, myoblasts did not increase proliferation with increasing ligand density on the low G-content alginates. Thus, alterations in the materials cell-binding ability cannot compensate for an inability of specific alginates to promote myoblast proliferation.

It is striking that with skeletal muscle cells a combination of high ligand density and high-G alginates are required to promote differentiation of the skeletal muscle cells (Figs. 3 and 4). Increasing the ligand density on low $G$ substrates by an order of magnitude cannot offset the downregulation of proliferation. In contrast to findings with other cell types, the differentiation of myoblasts increased with increasing ECM ligand densities on high G substrates. Previously, hepatocytes were shown to increase differentiation with decreasing adhesion ligand density, ${ }^{8}$ and endothelial cells differentiate maximally at intermediate levels of adhesion ligands. ${ }^{26}$ Together, these findings suggest 


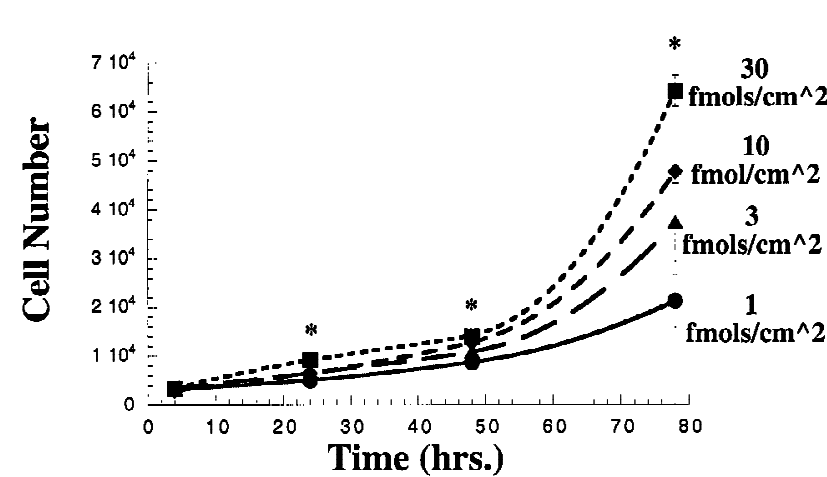

A
14 hours
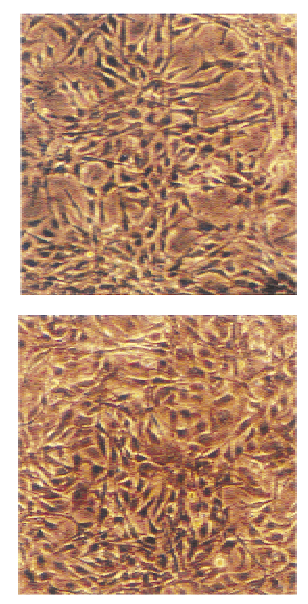

$10 \mathrm{fmol} / \mathrm{cm}^{\wedge} 2$ GGGGRGDY

\section{$100 \mathrm{fmol} / \mathrm{cm}^{\wedge} 2$ GGGGRGDY}

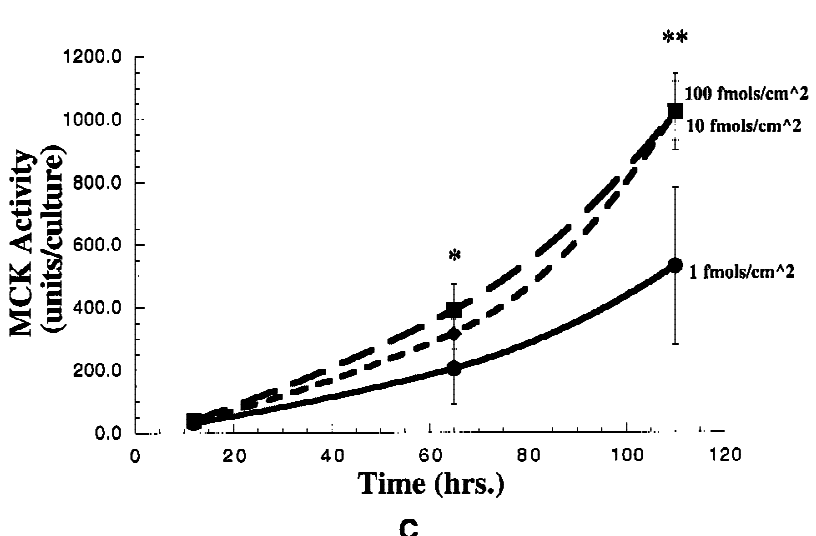

65 hours
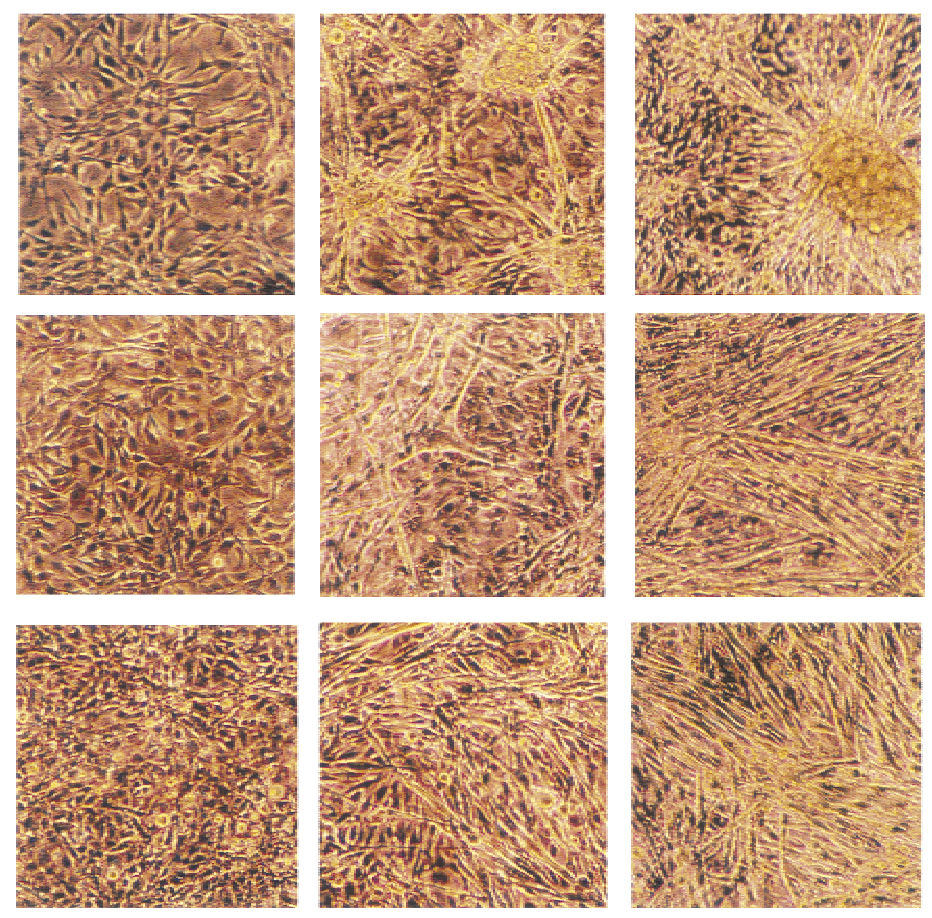

B

Figure 4. Myoblast proliferation and differentiation were dependent on the RGD-ligand density present on biomaterials of constant M:G ratio of 30:70. (A) Myoblast cell number increased over time, and the greatest proliferation was found with the highest ligand density. The range of density on the alginate surfaces was $1(\mathbf{O}), 3(\mathbf{\Delta}), 10(\boldsymbol{\bullet})$, and $30(\boldsymbol{\square}) \mathrm{fmol} / \mathrm{cm}^{2}$. *Statistically significant differences $(p<0.05)$ in cell counts between conditions. (B) Myoblast differentiation also increased with the substrate ligand density. Initial myoblast seeding densities were consistent between conditions, as determined with cell counts. The 10- and 100-fmol/ $\mathrm{cm}^{2}$ GGGGRGDY cultures differentiated by $65 \mathrm{~h}$, as exhibited by myoblast fusion into multinucleated myofibrils. The $1-\mathrm{fmol} / \mathrm{cm}^{2}$ cultures were less differentiated, and many multicellular aggregates formed with some fusion between aggregates. Many of the myoblasts on the low ligand density substrates pulled away from the substrates because of the low adhesion strength of the modified alginate. Myoblasts on the 10- and $100-\mathrm{fmol} / \mathrm{cm}^{2}$ density substrates were highly fused by the 110-h time point, whereas myoblasts on the low density substrates were still aggregated clusters with little fusion. (C) Muscle creatine kinase activity in the cultures indicated that the extent of differentiation of the 1 -fmol $/ \mathrm{cm}^{2}(\mathbf{)})$ ligand density cultures were significantly lower than the $10(\diamond)$ and $100(\boldsymbol{\square})$ fmol/ $\mathrm{cm}^{2}$ GGGGRGDY cultures, demonstrating a ligand density dependence on the extent of myoblasts differentiation. *, Statistically significant differences $(p<0.05)$ in creatine kinase activity between the highest modulus and the two low modulus conditions; $* *$, the 10- and $100-\mathrm{fmol} / \mathrm{cm}^{2}$ conditions are statistically different $(p<0.05)$ from the $1-\mathrm{fmol} / \mathrm{cm}^{2}$ condition. [Color figure can be viewed in the online issue, which is available at www.interscience.wiley.com.]

the dependence of cell function on the mechanics of the cell-biomaterial interaction may be cell-type dependent, with specific ranges of responsiveness for different cell types. Previous reports have docu- mented that the tractional forces exerted by cells on an adhesion substrate are also cell-type dependent, ${ }^{29}$ and we hypothesize that the magnitude of the forces exerted by specific cell types on the biomaterial may 
dictate the relevant range of ligand density to which the cells will respond.

These studies lead us to conclude that the material chemistry and ligand density are important for controlling the function of cells in contact with alginate matrices. The alginate system presented here may be readily used to present a variety of cell adhesion or cell signaling peptides (e.g., growth factors) directly to the biomaterial matrix, ${ }^{30}$ and these variables may be directly translated into in vivo experiments. These concepts suggest a fundamental requirement to match biomaterial composition to an intended cell response. Control over these variables may allow one to regulate targeted cell proliferation and differentiation as well as processes such as cell migration and apoptosis. ${ }^{5,25}$

\section{References}

1. Hubbell JA. Biomaterials for tissue engineering. BioTechnology 1995;13:565-576.

2. Langer R, Vacanti JP. Tissue engineering. Science 1993;26:920926.

3. Putnam AJ, Mooney DJ. Tissue engineering using synthetic extracellular matrices. Nat Med 1996;2:824-826.

4. Massia SP, Hubbell JA. An RGD spacing of $440 \mathrm{~nm}$ is sufficient for integrin $\alpha_{\mathrm{v}} \beta_{3}$-mediated fibroblast spreading and $140 \mathrm{~nm}$ for focal contact and stress fiber formation. J Cell Biol 1991;114: 1089-1100.

5. Chen CS, Mrksich M, Huang S, Whitesides GM, Ingber DE. Geometric control of cell life and death. Science 1997;276:14251428.

6. Mooney DJ, Hansen LK, Langer R, Vacanti JP, Ingber DE. Extracellular matrix controls tubulin monomer levels in hepatocytes by regulating protein turnover. Mol Biol Cell 1994;5: 1281-1288.

7. Ingber D. Integrins as mechanochemical transducers. Curr Opin Cell Biol 1991;3:841-848.

8. Huang S, Ingber DE. The structural and mechanical complexity of cell-growth control. Nat Cell Biol 1999;1:E131-E138.

9. Smidsrød O, Skjåk-Bræk G. Alginate as immobilization matrix for cells. TIBTECH 1990;8:71-78.

10. Martinsen A, Skjåk-Bræk G, Smidsrød O. Alginate as immobilized material: I. Correlation between chemical and physical properties of alginate gel beads. Biotechnol Bioeng 1989;33:7989.

11. Fremond B, Malandain C, Guyomard C, Chesne C, Guillouzo A, Campion J-P. Correction of bilirubin conjugation in the gunn rat using hepatocytes immobilized in alginate gel beads as an extracorporeal bioartificial liver. Cell Transplant 1993;2: 453-460.

12. Chang SCN, Rowley JA, Tobias G, Genes NG, Roy AK, Mooney DJ, Vacanti CA, Bonassar LJ. Injection molding of chondrocyte/alginate constructs in the shape of facial implants. J Biomed Mater Res 2001;55:503-511.

13. Hauselmann HJ, Masumd K, Hunziker EB, Neidhart M, Mok
SS, Michel BA, Thonar EJ-MA. Adult human chondrocytes cultured in alginate form a matrix similar to native human articular cartilage. Am J Physiol 1996;271:C742-C752.

14. Atala A, Kim W, Paige KT, Vacanti CA, Retik AB. Endoscopic treatment of vesicoureteral reflux with a chondrocyte-alginate suspension. J Urol 1994;152:641-643.

15. Espevik T, Otterlei M, Skjåk-Bræk G, Ryan L, Wright SD, Sundan A. The involvement of CD14 in stimulation of cytokine production by uronic acid polymers. Eur J Immunol 1991;23: 255-261.

16. Otterlei M, Ostgaard K, Skjaek-Braek G, Smidsrod O, SoonShiong P, Espevik T. Induction of cytokine production from human monocytes stimulated with alginate. J Immunother 1991;10:286-291.

17. Thomas A, Harding KG, Moore K. Alginates from wound dressings activate human macrophages to secrete tumor necrosis factor- $\alpha$. Biomaterials 2000;21:1797-1802.

18. Rowley JA, Mooney DJ. Alginate hydrogels as synthetic extracellular matrix materials. Biomaterials 1999;20:45-53.

19. Marler JJ, Guha A, Rowley JA, Bonassar L, Upton J, Mooney DJ, Vacanti JP. Soft-tissue augmentation with injectable alginate and syngeneic fibroblasts. Plastic Reconstr Surg 2000;105: 2049-2058.

20. Loebsack A, Greene K, Wyatt S, Culberson C, Austin C, Beiler R, Roland W, Eiselt P, Rowley J, Burg K, Mooney D, Holder W, Halberstadt C. In vivo characterization of a porous hydrogel material for use as a tissue bulking agent. J Biomed Mater Res 2001;57:575-581.

21. Alsberg E, Anderson K, Albeiruti A, Mooney, DJ. Cell interactive alginate hydrogels for bone tissue engineering. J Dent Res 2001;80:2025-2029.

22. Andres V, Walsh K. Myogenin expression, cell cycle withdrawal, and phenotypic differentiation are temporally separable events that precede cell fusion upon myogenesis. J Cell Biol 1996;132:657-666.

23. Chamberlain JS, Jaynes JB, Hauschka SD. Regulation of creatine kinase induction in differentiating mouse myoblasts. Mol Cell Biol 1985;5:484-492.

24. Pierschbacher MD, Ruoslahti E. Cell attachment activity of fibronectin can be duplicated by small synthetic fragments of molecule. Nature 1984;309:30-33.

25. Yao C-C, Ziober BL, Sutherland AE, Mendrick DL, Kramer RH. Laminins promote the locomotion of skeletal myoblasts via the alpha 7 integrin receptor. J Cell Sci. 1996;109:3139-3150.

26. Ingber DE, Folkman J. Mechanochemical switching between growth and differentiation during fibroblast growth factorstimulated angiogenesis in vitro: role of extracellular matrix. J Cell Biol 1989;109:317-330.

27. Lin CQ, Bissell MJ. Multi-faceted regulation of cell differentiation by extracellular matrix. FASEB J 1993;7:737-743.

28. Palecek SP, Loftus JC, Ginsberg MH, Lauffenburger DA, Horwitz AF. Integrin-ligand binding properties govern cell migration speed through cell-substratum adhesiveness. Nature 1997; 385:537-540.

29. Galbraith CG, Sheetz MP. A micromachined device provides a new bend on fibroblast traction forces. Proc Natl Acad Sci USA 1997;94:9114-9118.

30. Peters MC, Isenberg BC, Rowley JA, Mooney DJ. Release from alginate enhances the biological activity of VEGF. J Biomater Sci Polym Edn 1998;9:1267-1278. 